\title{
A AUTENTICIDADE DA PARTICIPAÇÃO CIDADÃ EM METODOLOGIAS PROJETUAIS
}

\section{THE AUTHENTICITY OF CITIZEN PARTICIPATION IN PROJECTUAL METHODOLOGIES}

\author{
A. Eleonora Paoli \\ PPGAU, Universidade Federal da Paraíba, Brasil \\ eleonora.paoli@academico.ufpb.br
}

\begin{abstract}
RESUMO
Este artigo busca investigar metodologias participativas empregadas na elaboração de diagnósticos e para levantamentos prévios a projetos de intervenção e/ou requalificação de espaços públicos em assentamentos vulnerabilizados. Para tal, foi realizado um estudo de caso no assentamento El Níspero, na cidade de Montería na Colômbia, onde foi concretizado um trabalho conjunto entre os moradores e uma equipe de arquitetos da Universidad del Sinú, tendo em vista a promoção de melhorias nos espaços públicos. Com o intuito de avaliar se a metodologia projetual possibilitou uma abertura maior ao envolvimento da comunidade, foi produzida uma matriz de análise da participação cidadã aplicável em outros estudos de caso. Os resultados do estudo mostram que, embora a participação não tenha sido constante nas diversas fases da metodologia participativa, esta gerou dados relevantes, complementando o diagnóstico realizado pela equipe e estreitando os laços de colaboração entre academia e comunidade.
\end{abstract}

Palavras-chave: participação cidadã, metodologias participativas, espaço público, assentamento vulnerabilizado.

Linha de Investigação: 1. Cidade e projeto. Tópico: Projeto urbano e espaço público.

\begin{abstract}
This article aims to analyze participatory methodologies used for the elaboration of diagnoses and for preliminary surveys of intervention and/or requalification projects of public spaces in vulnerable settlements. For that, it was carried out a case study in the El Níspero settlement, in the city of Montería, Colombia, where a joint work was carried out between the residents and a team of architects from Universidad del Sinú with a view to promoting improvements in public spaces. In order to assess whether the methodology allowed for greater openness to community involvement, it was produced a matrix of analysis of citizen participation applicable in other case studies. The results of the study show that, although participation was not constant in the different phases of the methodology, it generated relevant data, complementing the diagnosis made by the team and strengthening the collaboration between the university and the community.
\end{abstract}

Keywords: citizen participation, participatory methodologies, public spaces, vulnerable settlement.

Research line: 1. City and project. Topic: Urban design and public space. 


\section{XII

\section{Introdução}

Os avanços no âmbito da Participação Cidadã no planejamento urbano na Colômbia se concretizam com a Constituição de 1991. De acordo com o artigo 311, os municípios têm obrigação de ordenar o desenvolvimento do território e ao mesmo tempo promover a Participação Cidadã. Entretanto, apesar das disposições constitucionais, essas podem estar associadas a instrumentos mais consultivos do que decisórios, resultando em uma participação fictícia (Urrego, 2017). Nesta perspectiva, metodologias participativas empregadas em projetos urbanos são instrumentos que podem viabilizar a construção de pactos entre os agentes sociais envolvidos. Contudo, a sua aplicação não garante uma "participação autêntica", ou seja, o envolvimento ativo dos sujeitos, demarcado pelo efetiva tomada de decisões e pela redução dos processos de exclusão.

Em particular, este trabalho toma como estudo de caso o bairro El Níspero, na cidade de Montería na Colômbia. Vale mencionar que as disposições do instrumento de planejamento do município - denominado Plan de Ordenamiento Territorial (POT) - contrastam com as iniciativas executadas em El Níspero anteriores a 2018. O artigo 26 do POT, por exemplo, afirma a obrigatoriedade da participação e da aprovação da comunidade para o desenho e a gestão de parques urbanos e espaços públicos, o que não aconteceu com a implementação do Parque El Níspero pela Prefeitura em 2015.

Sendo assim, em 2018, a liderança popular do bairro buscou a interação com entidades públicas e privadas Universidade e Prefeitura - com o intuito de destacar a precariedade das condições de vida de seus moradores. Nessas circunstâncias, a Facultad de Arquitetura da Universidad del Sinú, em Montería, se interessou pelo caso de El Níspero e colocou-se à disposição para realizar um trabalho conjunto com os moradores, que teve como objetivo, através de metodologias que serão descritas e analisadas a seguir, gerar um diagnóstico das condições do bairro e propostas de intervenções para melhoria dos espaços públicos. Dessa forma, o objetivo deste estudo foi o de avaliar se essas metodologias possibilitaram uma abertura maior ao envolvimento da comunidade ou acabaram limitando-o.

De fato, a vivência direta ${ }^{2}$ da tentativa de implementação de práticas cidadãs despertou questionamentos sobre a relação entre as metodologias e seus resultados, sugerindo a hipótese de que inconvenientes, ou mesmo sua condução e elaboração, poderiam ter sido melhor direcionados. Nesse sentido, este artigo pode contribuir como referência e suporte para o desenvolvimento de metodologias participativas que auxiliem a prática projetual no entendimento da realidade implicada e do modo de habitar das comunidades vulnerabilizadas.

No que se refere aos procedimentos metodológicos, o aporte deste estudo consiste na criação de uma matriz geral de análise da participação da comunidade baseada em nove parâmetros - a serem aplicados em suas diversas fases de Preparação, Aplicação e Sistematização de resultados - enquadrados entre dois polos de participação e não-participação. A matriz fruto desse trabalho foi pensada de maneira a viabilizar sua aplicação futura em diversos estudos de caso - colombianos ou não. Por último, serão descritas as atividades que compõem a metodologia participativa empregada em El Níspero em março de 2018,

\footnotetext{
${ }^{1}$ Se assume, nesse trabalho, a tradução literal do termo colombiano Participación Ciudadana (Participação Cidadã), conceito expresso no Brasil através do termo "Participação Popular".

${ }^{2}$ O interesse no tema vem em função de uma experiência de estágio na Colômbia entre setembro 2017 e março 2018, na Facultad de Arquitetura da Universidad del Sinú em Montería.
} 


\section{SÃO PAULO15 $\sim 17 \cdot$ LISBOA $25 \sim 26$ JUN 2020

retomando as três fases em que ocorreu, e serão avaliadas a partir do grau de envolvimento da comunidade em relação aos nove parâmetros da matriz, mostrando avanços e/ou retrocessos em relação à participação da comunidade nas etapas pré-projeto.

Entretanto, antes de iniciar tal empreitada, é importante orientar o leitor no contexto histórico e socioespacial em que se situa o bairro El Níspero, na cidade colombiana de Montería, que será objeto deste estudo. O ano de formação do assentamento El Níspero em 2002 coincide com uma das ondas mais fortes de desplazamiento (remoção, deslocamento forçado) no território colombiano, razão pela qual uma quantidade significativa de pessoas foi forçada a abandonar suas casas em direção aos centros urbanos. No caso de Montería, as famílias desplazadas foram assentados pela Prefeitura em um loteamento na margem do perímetro urbano e vêm sofrendo desde então as consequências da vulnerabilidade socioeconômica somada à falta de assistência pelo poder público.

Os resultados do estudo de caso mostram que, embora a participação tenha sido decrescente na sequência das fases de Preparação, Aplicação e Sistematização, a metodologia participativa gerou dados relevantes, complementando o diagnóstico realizado pela equipe e estreitando os laços de colaboração entre academia e a comunidade. Entretanto, resultou claro que o diagnóstico do bairro não esteve tão tangível na elaboração da metodologia como deveria. De fato, as consequências do desplazamiento, a sensibilidade ambiental, a coesão social, entre outras características que conformam a comunidade, não foram abordadas nem exploradas pela metodologia. A contribuição desse trabalho pretende ser a de orientar futuras práticas cidadãs em direção a uma participação mais autêntica e específica para comunidades em situação de vulnerabilidade.

\section{A matriz de análise de metodologias participativas}

Com o termo "metodologias participativas", entendemos o conjunto de práticas, ferramentas e técnicas usadas para a tomada de decisão sobre temas de interesse público por parte de atores sociais, de maneira a promover sua participação ativa e uma distribuição mais equilibrada de poderes. (Santos, 2005). Uma vez entendido que por metodologia não nos referimos apenas a atividades isoladas, mas sim a um processo geral que engloba aspectos de sua Preparação, Aplicação e Sistematização, a matriz foi criada de forma a refletir essas três fases do processo. A Preparação consiste tanto na elaboração da metodologia e na convocação dos participantes antes da sessão quanto na sua organização no dia do encontro (Parâmetros 1 e 2). Já os parâmetros relativos à Aplicação se referem a tempo e lugar de aplicação e à linguagem usada tanto no material quanto pelos aplicadores durante a sessão (Parâmetros 3, 4, 5 e 6). Por último, a Sistematização faz referência à maneira como ocorreu a compilação dos resultados após a sessão e ao retorno para a comunidade para sua aprovação e livre acesso às informações (Parâmetros 7, 8 e 9).

\subsection{Parâmetro 1: Elaboração da metodologia}

O primeiro parâmetro refere-se à própria construção de práticas cidadãs, antes mesmo de sua aplicação. Para além das referências utilizadas - exemplos de metodologias já reconhecidas e legitimadas como participativas - é levado em conta o ambiente e as pessoas que tiveram contribuição nesse processo, ou seja, se nessa fase houve colaboração da comunidade ou o aporte ficou restrito apenas à academia ou instituição promotora. $O$ ensaio das práticas em pequena escala antes da sessão geral, permitindo assim eventuais correções, é outro aspecto a ser considerado nesse parâmetro. Por último, esse parâmetro resulta 


\section{SÃO PAULO15 $\sim 17 \cdot$ LISBOA $25 \sim 26$ JUN 2020

importante à medida que mostra se a metodologia reflete a realidade descrita nos diagnósticos já disponíveis sobre determinada comunidade e território e se se desenvolve a partir dela, ou seja, se há um conhecimento prévio tanto do ambiente quanto da história da comunidade.

\subsection{Parâmetro 2: Organização dos participantes}

Esse parâmetro refere-se à maneira como foram convidados, escolhidos e em seguida repartidos os participantes da sessão, levando em conta fatores como sexo, idade, ocupação, etc. A aleatoriedade ou supervisão na organização das pessoas, bem como o fato deles serem voluntários ou não, interfere na distribuição equitativa em grupos e, portanto, nos resultados finais das práticas. O número total de pessoas e a quantidade por grupo também resultam importantes - bem como o equilíbrio entre organizadores e participantes -, já que grupos muito grandes não propiciam a participação unânime e equilibrada. Além disso, a maneira como os moradores foram informados e convidados à atividade metodológica indica o grau de colaboração entre comunidade e a academia ou instituição promotora na fase de preparação da sessão.

\subsection{Parâmetro 3: Ambiente de aplicação}

Esse parâmetro refere-se ao meio físico em que foram postas em prática as metodologias, tanto do posto de vista da ergonomia e conforto quanto da sensação de familiaridade ou estranhamento que o ambiente pode causar. Um ambiente próximo à realidade das pessoas e com o qual elas se identifiquem pode influenciar de forma positiva o rendimento das práticas, enquanto o incômodo provocado por um espaço inadequado e adverso pode comprometê-las. Não somente o lugar em si, mas também quem escolheu e preparou o lugar antes da sessão são fatores importantes a serem considerados.

\subsection{Parâmetro 4: Tempo de aplicação}

O quarto parâmetro faz referência à duração das atividades metodológicas durante a sessão, uma vez que uma quantidade de tempo adequada consegue manter as pessoas envolvidas e interessadas no processo, enquanto extrapolando esse tempo a sessão gera exaustão nos participantes e compromete assim seus resultados. Ainda pode-se considerar se houve um recesso para descanso durante a sessão. A escolha da data do encontro e o momento do dia em que ocorreu - manhã, tarde ou noite -, também devem ser considerados, já que isso pode propiciar uma maior participação da comunidade ou limitá-la.

\subsection{Parâmetro 5: Linguagem do material}

Esse parâmetro refere-se à compreensibilidade do material entregue aos participantes para o desenvolvimento das atividades durante a sessão. $O$ uso tanto de uma linguagem quanto de uma estética próxima à realidade das pessoas, e que reflete seus modos de vida, configura-se como mais acessível e, portanto, mais estimulante para eles. Ao contrário, uma linguagem complexa - levando em conta, por exemplo, o nível de escolaridade, a faixa etária do grupo ou as tradições locais - pode desmotivar a pessoa e prejudicar seu rendimento. A capacidade e disponibilidade do indivíduo para ler e/ou escrever também deve ser levada em conta durante a elaboração da atividade.

\subsection{Parâmetro 6: Linguagem do aplicador}

Esse parâmetro refere-se à abordagem e à linguagem usada pelos aplicadores durante as sessões. Assim como a linguagem do material, a fala empregada durante as atividades precisa ser acessível e compreensível pelos participantes. Uma linguagem técnica, que se afasta dos modos de falar do dia a dia, 


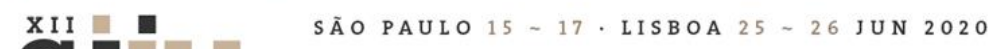

resulta ineficaz para atingir seu interesse e colaboração. Além disso, caso haja alguma sessão infantil, é recomendada a assistência de um profissional do campo da pedagogia para auxiliar na supervisão das crianças. De maneira geral, é recomendado que os aplicadores saibam se relacionar bem tanto com crianças quanto com adultos.

\subsection{Parâmetro 7: Compilação dos resultados}

Esse parâmetro refere-se à interferência que o indivíduo, ou grupos de indivíduos, responsáveis por compilar os dados oriundos das atividades, pode ter no resultado final do estudo. A imparcialidade de quem relata e compila as informações ou a simples sensibilidade para o entendimento dos resultados finais gera maior assertividade no diagnóstico final e na proposta de intervenção. Ainda nessa fase, a colaboração de membros da comunidade pode elucidar certos aspectos e ajudar a reportá-los da forma mais adequada além de contribuir para o aprofundamento do sentimento de pertença durante as distintas etapas do processo.

\subsection{Parâmetro 8: Aprovação final}

O oitavo parâmetro refere-se à aceitação e aprovação final por parte da comunidade do produto das atividades. Mais especificamente, é avaliado se essa etapa está incluída na própria metodologia e de que forma é realizada. De certa forma, isso permite tanto esclarecer alguns aspectos que não tenham ficados convincentes durante a compilação quanto corrigir eventuais incoerências e legitimar o produto final.

\subsection{Parâmetro 9: Livre Acesso às informações e controle social}

O último parâmetro serve para entender se, após a compilação dos resultados, estes são disponibilizados para a comunidade ou se seu uso fica circunscrito à academia. Além disso, é avaliado se a comunidade tem possibilidade de exercer controle social sobre os resultados finais, podendo acessá-los, discuti-los e exigindo determinadas alterações, mesmo após o encerramento da sessão. O controle social implica a integração entre a sociedade civil e a entidade promotora, sendo por esse motivo de extrema importância.

\section{$2.10 \quad$ A matriz}

A Tabela 01 abaixo, além de apresentar os parâmetros criados - de acordo com as três fases já mencionadas - indica os extremos ${ }^{3}$ possíveis no que diz respeito à participação, o que permite avaliar se determinado parâmetro possui elementos que o caracterizam como participativo ou não participativo.

\footnotetext{
${ }^{3}$ Vale mencionar que esta forma de classificação e análise dos parâmetros entre 'extremos' foi baseada na matriz proposta pelo geografo Klemens Laschefski (2002); (2006), que avalia a sustentabilidade dos sistemas de ação geográfica sob uma perspectiva dialética.
} 


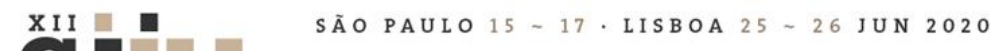

\begin{tabular}{|c|c|c|c|}
\hline $\begin{array}{l}P \\
R \\
E\end{array}$ & $\begin{array}{c}1 . \\
\text { Elaboração } \\
\text { da } \\
\text { metodologia }\end{array}$ & $\begin{array}{c}\text { Colaborativa: quando ocorre a } \\
\text { contribuição de pessoas tanto da } \\
\text { academia e/ou instituições promotoras } \\
\text { quanto da comunidade no processo de } \\
\text { elaboração da metodologia; é previsto } \\
\text { um ensaio em pequena escala antes } \\
\text { da sessão para eventuais correções. } \\
\text { Baseia-se no conhecimento prévio da } \\
\text { comunidade. }\end{array}$ & $\begin{array}{l}\text { Restrita: acontece quando apenas a } \\
\text { academia e/ou instituições promotoras } \\
\text { desenvolvem a metodologia, sendo } \\
\text { aplicada de maneira hierárquica. Os } \\
\text { objetivos das atividades não são } \\
\text { criados e compartilhados com a } \\
\text { comunidade, nem testados antes da } \\
\text { sessão geral. Não leva em conta a } \\
\text { realidade e a história da comunidade. }\end{array}$ \\
\hline $\begin{array}{l}\mathrm{A} \\
\mathrm{C} \\
\tilde{\mathrm{A}} \\
\mathrm{O}\end{array}$ & $\begin{array}{c}2 . \\
\text { Organização } \\
\text { dos } \\
\text { participantes }\end{array}$ & $\begin{array}{c}\text { Equitativa: as pessoas são convidadas } \\
\text { e escolhidas de forma a manter uma } \\
\text { distribuição equilibrada quanto a } \\
\text { determinadas variáveis (sexo e idade, } \\
\text { por exemplo, mas a depender dos } \\
\text { objetivos) dos participantes dos grupos. } \\
\text { Estes devem estar cientes dos } \\
\text { objetivos das atividades. O tamanho } \\
\text { dos grupos deve garantir participação } \\
\text { ativa de todos. }\end{array}$ & $\begin{array}{c}\text { Irregular: os participantes são } \\
\text { divididos em grupos aleatoriamente } \\
\text { e/ou sem critérios, gerando certa } \\
\text { disparidade, além de seu número não } \\
\text { ser adequado. Estes não são } \\
\text { informados previamente sobre o intuito } \\
\text { do encontro. }\end{array}$ \\
\hline $\begin{array}{l}\mathrm{A} \\
\mathrm{P}\end{array}$ & $\begin{array}{c}3 . \\
\text { Ambiente de } \\
\text { aplicação }\end{array}$ & $\begin{array}{l}\text { Receptivo: ambiente próximo à } \\
\text { realidade da comunidade, de fácil } \\
\text { acesso, confortável e adequado para o } \\
\text { tipo de atividades. Envolve todas as } \\
\text { necessidades básicas - iluminação, } \\
\text { sanitários, água, etc. }\end{array}$ & $\begin{array}{c}\text { Desconfortável: ambiente } \\
\text { descuidado, mal iluminado, bagunçado } \\
\text { e carente de serviços básicos. Sem } \\
\text { funcionalidade e afetividade que } \\
\text { estimule o bem-estar dos } \\
\text { participantes. }\end{array}$ \\
\hline $\begin{array}{l}\mathrm{C} \\
\mathrm{A} \\
\mathrm{C} \\
\tilde{\mathrm{A}} \\
\mathrm{O}\end{array}$ & $\begin{array}{c}4 . \\
\text { Tempo de } \\
\text { aplicação }\end{array}$ & $\begin{array}{l}\text { Pertinente: o tempo da atividade é } \\
\text { suficiente para a realização das etapas } \\
\text { previstas e adequado para manter a } \\
\text { concentração dos participantes durante } \\
\text { toda a sessão. O dia e o horário da } \\
\text { sessão favorecem a participação do } \\
\text { maior número de pessoas. }\end{array}$ & $\begin{array}{l}\text { Inapropriado: o tempo da atividade é } \\
\text { muito maior ou muito menor do que o } \\
\text { necessário e sem recesso durante a } \\
\text { sessão, tornando-se extenuante para } \\
\text { os participantes. O dia e o horário da } \\
\text { sessão restringem a participação da } \\
\text { comunidade. }\end{array}$ \\
\hline & $\begin{array}{c}5 . \\
\text { Linguagem } \\
\text { do material }\end{array}$ & $\begin{array}{l}\text { Compreensível: linguagem e estética } \\
\text { do material adequadas ao nível de } \\
\text { escolaridade, idade e origem dos } \\
\text { participantes, refletindo a variedade } \\
\text { linguística e social de forma a ser } \\
\text { acessível a todos. }\end{array}$ & $\begin{array}{c}\text { Incompreensível: vocabulário } \\
\text { complexo e técnico do material, além } \\
\text { de distante da realidade dos } \\
\text { participantes, sem nenhum elemento } \\
\text { que provoque um sentimento de } \\
\text { identificação. }\end{array}$ \\
\hline
\end{tabular}




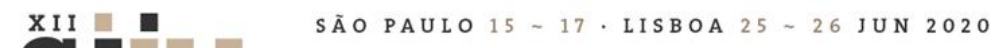

\begin{tabular}{|c|c|c|c|}
\hline & $\begin{array}{c}6 . \\
\text { Linguagem } \\
\text { do aplicador }\end{array}$ & $\begin{array}{c}\text { Familiar: o aplicador sabe se } \\
\text { relacionar bem com os participantes, } \\
\text { utilizando uma linguagem simples e } \\
\text { próxima a eles, falando de maneira } \\
\text { clara e calma. Caso haja sessão } \\
\text { infantil, as crianças são assistidas por } \\
\text { um pedagogo. }\end{array}$ & $\begin{array}{l}\text { Estranha: linguagem excessivamente } \\
\text { técnica, com referências } \\
\text { incompreensíveis aos participantes. O } \\
\text { aplicador fala rapidamente e não sabe } \\
\text { lidar com adultos e crianças. }\end{array}$ \\
\hline $\begin{array}{l}\text { I } \\
\text { S }\end{array}$ & $\begin{array}{l}7 . \\
\text { Compilação } \\
\text { do } \\
\text { diagnóstico }\end{array}$ & $\begin{array}{l}\text { Assertiva: o relator participou das } \\
\text { atividades, descrevendo de forma } \\
\text { imparcial os resultados da sessão. É } \\
\text { ajudado por membros da comunidade } \\
\text { durante essa fase, o que torna a } \\
\text { transcrição mais completa. }\end{array}$ & $\begin{array}{l}\text { Duvidosa: o relator se ocupa da } \\
\text { compilação isoladamente, sem ter feito } \\
\text { parte da sessão e da elaboração das } \\
\text { metodologias. A sua compreensão dos } \\
\text { fatos é incompleta e tendenciosa. Não } \\
\text { há a participação de membros da } \\
\text { comunidade. }\end{array}$ \\
\hline $\begin{array}{l}\mathrm{E} \\
\mathrm{M} \\
\mathrm{A} \\
\mathrm{T}\end{array}$ & $\begin{array}{c}8 . \\
\text { Aprovação } \\
\text { final }\end{array}$ & $\begin{array}{l}\text { Interativa: os resultados da sessão } \\
\text { voltam para discussão e aprovação } \\
\text { final da comunidade, a qual é } \\
\text { consultada para a elaboração da } \\
\text { versão final do diagnóstico e da } \\
\text { proposta de intervenção. }\end{array}$ & $\begin{array}{l}\text { Excludente: uma vez encerrada a } \\
\text { sessão, os grupos não recebem um } \\
\text { retorno sobre o resultado final que não } \\
\text { é aprovado nem legitimado pela } \\
\text { comunidade. }\end{array}$ \\
\hline $\begin{array}{l}\mathrm{A} \\
\mathrm{C} \\
\tilde{\mathrm{A}} \\
\mathrm{O}\end{array}$ & $\begin{array}{l}9 . \\
\text { Livre acesso } \\
\text { às } \\
\text { informações } \\
\text { e controle } \\
\text { social }\end{array}$ & $\begin{array}{c}\text { Efetivo: a comunidade tem acesso aos } \\
\text { dados e resultados da atividade } \\
\text { metodológica, podendo consultá-los e } \\
\text { discuti-los novamente, exigindo } \\
\text { eventuais alterações. }\end{array}$ & $\begin{array}{l}\text { Precário: a comunidade não recebe } \\
\text { os dados e resultados da atividade } \\
\text { metodológica e não tem possibilidade } \\
\text { de questioná-los e de exercer o } \\
\text { controle social. }\end{array}$ \\
\hline
\end{tabular}

Tabela 01. Parâmetros de análise da participação. Fonte: Elaboração própria. 


\section{SÃOPAULO15 $17 \cdot$ LISBOA $25 \sim 26$ JUN 2020}

\section{As metodologias participativas desenvolvidas em El Níspero}

\subsection{A fase de Preparação}

A equipe de Preparação foi integrada por seis representantes da Universidad del Sinú, que desenvolveram a metodologia dentro da academia, a partir de algumas referências no âmbito da participação que foram readaptadas para os objetivos da sessão. Ao encontro estiveram presentes voluntariamente crianças e adolescentes, integrando um grupo de cerca sessenta pessoas entre os 6 e os 14 anos de idade.

\subsection{A fase de Aplicação}

A Sessão Participativa Infantil ocorreu em uma das igrejas da comunidade e teve uma duração total de aproximadamente quatro horas, incluindo o tempo de um breve intervalo. Junto à equipe da Universidad, na fase de Aplicação e de preparação do lugar cooperaram uma pedagoga e um líder da comunidade.

A atividade 1 teve como objetivo o entendimento da relação entre a comunidade infantil e o uso do espaço público. A todos os grupos foram entregues três cartolinas e uma foto dos três espaços públicos do bairro, além de post-its e canetas; cada cartolina foi usada para um bloco de perguntas (bloco 1, 2 e 3) e para cada resposta do bloco foi usada uma cor diferente de post-it.

- Bloco 1: Olhando para a foto da praça, escrevam: a). Quais palavras pensam quando olham para essa foto; b). O que mais gostam desse espaço; c). O que menos gostam desse espaço; d). O que fazem nesse espaço.

- Bloco 2: Escrevam: a). O que mais gostam do bairro onde moram; b). O que menos gostam do bairro onde moram; c). Quais atividades realizam no bairro onde moram; d). $\mathrm{O}$ que falta no bairro onde moram.

- Bloco 3: Escrevam: a). Qual cor gostam mais; b). O que fazem geralmente no tempo livre; c). Quais atividades realizam em outros bairros da cidade; d). Um lugar de diversão na cidade onde vão com frequência e porquê.

Já a atividade 2 teve como objetivo descobrir as intenções e as preferências dos participantes com vistas a elaborar uma proposta para os espaços públicos a partir das necessidades da comunidade infantil. Foram distribuídas, assim, quatro cartolinas pequenas e tintas e pincéis para cada grupo, sendo cada uma destinada a desenhar, pintar e escrever a resposta para essas perguntas: a). Os jogos que mais gostam; $b$ ). Os esportes que mais gostam; c). Inventem um jogo que gostariam de fazer na quadra; d). Se pudessem desenhar a rua onde moram, como seria e o que teria?

\subsection{A fase de Sistematização}

Uma vez encerrada a sessão, os coordenadores de cada grupo relataram algumas considerações finais sobre as discussões e guardaram as cartolinas de acordo com a cor dos grupos dentro da Universidad, depois de escaneá-las e armazená-las em uma nuvem virtual.

\subsection{A análise com base na matriz}

\subsubsection{Elaboração da metodologia}




\section{SÃO PAULO15 $\sim 17 \cdot$ LISBOA $25 \sim 26$ JUN 2020

Em relação ao primeiro parâmetro, foi observado que nem a atividade 1 nem a 2 trouxeram elementos que comprovassem o conhecimento prévio sobre a realidade física e socioeconómica da comunidade. Tendo vivenciado a fase de Preparação, é certo que houve uma pesquisa aprofundada sobre o ambiente do bairro, enquanto a história da comunidade em si - levando em conta o fator do desplazamiento, por exemplo, não foi focado nas atividades. Deste modo, podemos ressaltar que ambas as atividades configuram uma metodologia genérica que poderia ser reproduzida em outros contextos não necessariamente ligados a El Níspero, provavelmente devido à ausência de integrantes da comunidade nessa fase. Ainda ressaltamos que não houve um ensaio da metodologia antes da aplicação geral e concluímos que nenhuma das duas atividades teve uma elaboração colaborativa, ao contrário, essa ficou restrita ao âmbito acadêmico e apenas repassada à comunidade para que enviasse seus participantes.

\subsubsection{Organização dos participantes}

As atividades 1 e 2 podem ser colocadas no mesmo patamar em relação a esse parâmetro, já que foram desenvolvidas no mesmo dia e pelos mesmos grupos. A convocatória de participantes foi realizada pelos líderes da comunidade durante umas das reuniões do bairro a pedido da equipe da Universidade e, no dia da sessão, foi supervisionada a quantidade máxima de sessenta crianças através de um cadastro, não sendo impedida a entrada de ninguém. Entretanto, esse número total resultou inapropriado em função da idade das pessoas, do material, do espaço e da equipe disponível. As crianças menores ou as mais tímidas acabaram se envolvendo menos dentro do próprio grupo pois as crianças maiores se sobressaiam. Provavelmente, a aleatoriedade da distribuição dos grupos pode ter causado essa irregularidade. A organização tendeu, portanto, a ser irregular no quesito da distribuição e ao mesmo tempo equitativa no que se refere à convocação dos participantes.

\subsubsection{Ambiente de aplicação}

A igreja onde foram realizadas as atividades 1 e 2, apesar de ter uma decoração discreta com alguns elementos coloridos, é uma construção com alvenaria aparente, telha metálica e sem janelas para iluminação natural e ventilação adequada, o que, associado ao clima tórrido, comprometeu o conforto térmico durante a sessão tanto para os participantes quanto para os organizadores. A iluminação e ventilação artificias também resultaram insuficientes. Além disso, cada grupo tinha à disposição apenas uma mesa e seis cadeiras de plástico, o que tornou difícil a escrita das crianças durante a atividade. Entretanto, por se localizar no bairro, em um ponto de fácil acesso, o ambiente era receptivo e acessível por gerar uma sensação de familiaridade e segurança. Os líderes ajudaram tanto na escolha do lugar quanto na preparação no dia da sessão, providenciando mesas, cadeiras e lanches, e estando presente quando as crianças chegaram e foram embora. O ambiente possui, portanto, características tanto de desconforto quanto de receptividade.

\subsubsection{Tempo de aplicação}

O dia de realização das atividades 1 e 2 foi um sábado pela manhã, momento no qual as crianças não desempenham atividades escolares, o que não trouxe restrições à participação. Entretanto, a duração da sessão foi muito extensa, gerando cansaço e desatenção nas crianças e se tornando extenuante também para os organizadores, o que configurou um tempo total de aplicação inapropriado. Entretanto, em relação à atividade 2, ela ocorreu mais rapidamente - sendo mais lúdica e prática - e, portanto, resultou mais pertinente e adequada à faixa etária dos participantes do que a atividade 1 . $O$ fato dela ter ocorrido após o 


\section{SÃOPAULO15 $\quad$ SA LISBOA $25 \sim 26$ JUN 2020}

recesso também pode ter influenciado positivamente, uma vez que as crianças haviam tido um momento de descontração. Contudo, em nenhuma das duas atividades foi possível a realização da fase final de discussão em grupo, deixando a metodologia incompleta, uma vez que a atenção das crianças já havia sido comprometida pelo tempo de aplicação.

\subsubsection{Linguagem do material}

No que se refere à modalidade e à linguagem do material, a atividade 2 resultou mais compreensível e adequada à faixa etária das pessoas, uma vez que foi baseada na ação de desenhar e pintar mais do que na de escrever. Algumas crianças, de fato, não sabiam escrever ainda, o que limitou o envolvimento delas na atividade 1. Esse fator está estritamente ligado ao parâmetro 1 referente à elaboração da metodologia. Mesmo que o coordenador as ajudasse a transpor seu pensamento escrevendo no lugar delas, esse fator mostrou-se desestimulante para a criança no restante da atividade. No que se refere à aplicação das perguntas tanto da atividade 1 quanto da 2, cada coordenador as formulava verbalmente para o próprio grupo de uma maneira diferente de como reportadas acima, tornando o material mais compreensível. 0 material empregado em ambas as atividades não possuía uma estética que fosse próxima à realidade dos participantes, o que não tornou o material atrativo, porém tampouco complexo e incompreensível.

\subsubsection{Linguagem do aplicador}

Os aplicadores das atividades 1 e 2 foram os próprios coordenadores dos grupos, que não possuíam preparação pedagógica, porém se relacionaram bem com as crianças. $O$ fato da maioria deles serem de Montería caracterizou uma fala e uma expressão mais familiar às crianças. A cooperação de uma pedagoga foi fundamental durante a aplicação, especialmente quando a atenção das crianças se desviava das atividades, apesar de ter sido apenas uma profissional para todos os grupos. Não foi utilizada uma linguagem técnica e estranha durante a sessão, entretanto foi preciso cuidado na maneira de dirigir as perguntas, já que isso poderia simplesmente confirmar uma resposta em vez de estimular uma nova consciência para novas questões.

\subsubsection{Compilação dos resultados}

Essa fase ocorreu apenas dentro da academia, sendo realizada pelos coordenadores e discutida em conjunto. $O$ fato deles terem feito parte da fase de Aplicação - mesmo que não todos estiveram na fase de Preparação -, contribuiu para uma compilação dos dados mais assertiva. De fato, a interpretação de algumas respostas e desenhos foi possível só graças à presença do coordenador. Entretanto, a compilação dos resultados não envolveu nenhum integrante da comunidade, reduzindo assim seu sentimento de pertença e gerando interpretações apenas de fora para dentro. Quanto à assertividade dos resultados, a atividade 2 resulta mais aberta a interpretações, uma vez que se baseia em desenhos e pinturas, enquanto a atividade 1 é menos duvidosa já que se exprime com palavras.

\subsubsection{Aprovação final}

Não houve aprovação final dos resultados compilados após a sessão, o que torna ainda mais excludente a fase de Sistematização dessa metodologia. A comunidade nunca recebeu um retorno sobre os dados das atividades 1 e 2, excluindo assim a possibilidade de uma aprovação final interativa. 


\section{SÃOPAULO15 $17 \cdot$ LISBOA $25 \sim 26$ JUN 2020}

\subsubsection{Livre acesso às informações e controle social}

Os resultados nunca foram entregues à comunidade e, portanto, não houve um efetivo acesso a eles. Sem a possibilidade de aceder, tampouco foi possível exercer controle social sobre as iniciativas que foram tomadas a partir das sessões, envolvimento que resultou, portanto, precário em ambas as atividades 1 e 2.

\section{Considerações finais}

A fase de Preparação resultou ser pouco colaborativa, especialmente durante a elaboração da metodologia, embora vale lembrar que o primeiro contato havia sido realizado pela liderança do bairro. A organização dos participantes demonstrou a colaboração e interesse livre da comunidade na fase de convocatória, enquanto a distribuição de crianças nos grupos não ocorreu de maneira equitativa limitando o envolvimento de todos..

Já na Aplicação, observa-se uma maior abertura à participação, especialmente em relação à linguagem do material e do aplicador. $\mathrm{O}$ ambiente e o tempo de aplicação situaram-se em um patamar intermédio de efetividade, possuindo características tanto de desconforto quanto de pertinência.

Por último, a Sistematização não apresentou quase nenhuma característica de participação, à medida que os resultados da compilação - que ocorreu sem nenhum integrante da comunidade -, nunca foram disponibilizados para a comunidade e passaram por uma aprovação final, restringindo assim o envolvimento popular na tomada de decisões.

Apesar das disposições claras dos instrumentos legislativos, a participação cidadã no âmbito do planejamento urbano é passível de questionamentos à medida que possui diferentes estágios de autenticidade. A contribuição desse trabalho pretende ser a de orientar a condução de futuras metodologias como maneira de compreender a realidade de comunidades em situação de vulnerabilidade e projetar espaços públicos de acordo com suas formas de viver e habitar.

\section{Referências bibliográficas}

BROSE, Markus (Org.) (2010). Metodologia participativa: uma introdução a 29 instrumentos. Porto Alegre: Tomo Editorial.

FARIA, A. A. \& FERREIRA NETO, P. (2005). Ferramentas de diálogo. Brasília: IEB.

LASCHEFSKI, K. (2002). Nachhaltige Entwicklung durch Forstwirtschaft in Amazonien? Geographische Evaluierungen des Forest Stewardship Council. Tese de Doutorado - Universität Heidelberg. - (2006). A sustentabilidade geográfica de condomínios na zona metropolitana de Belo Horizonte. In: COSTA, H. S. M. et al. (Orgs.). Novas periferias metropolitanas. (313-338). Belo Horizonte: Editora C/ Arte.

MONTERÍA. Plan de Ordenamiento Territorial para el Municipio de Montería. 2002-2015.

RISLER, J. \& ARES, P. (2013). Manual de mapeo colectivo: recursos cartográficos críticos para procesos territoriales de creación colaborativa. Buenos Aires: Tinta Limón.

SANTOS, A. D. (Org.) (2005). Metodologias participativas: caminhos para o fortalecimento de espaços públicos socioambientais. São Paulo: Peirópolis. 


\section{XII}

Seminario Internacional de Investigação em Urbanismo Investigación en Urbanismo

SOUZA, M. L. (2003). Mudar a Cidade: Uma Introdução Crítica ao Planejamento e à Gestão Urbanos. Rio de Janeiro: Bertrand Brasil.

URREGO, G. (2017). Interdependencias y rupturas de la participación y planeación del territorio en Colombia, a partir de 1991. Revista Katharsis (Envigado), 23, 236-259. 